\title{
Twin-Twin transfusion syndrome: a case report
}

\section{Romi Bansal, Jasleen Kaur, Priyanka*}

Department of Obstetrics and Gynecology, Adesh Institute of Medical Sciences and Research, Bathinda, Punjab, India

Received: 19 December 2019

Revised: 18 January 2020

Accepted: 24 January 2020

\section{*Correspondence:}

Dr. Priyanka,

E-mail: priyanka.garg.u@gmail.com

Copyright: (c) the author(s), publisher and licensee Medip Academy. This is an open-access article distributed under the terms of the Creative Commons Attribution Non-Commercial License, which permits unrestricted non-commercial use, distribution, and reproduction in any medium, provided the original work is properly cited.

\begin{abstract}
Twin to twin transfusion syndrome is a rare but serious complication of monochorionic twin pregnancy. It is characterized by the development of abnormal placental vascular communication from one foetus (donor) to the other foetus (recipient). If left untreated it led to high rates of perinatal morbidity and mortality due to its poorly understood etiology and difficulty in diagnosing and treatment. Authors report a case of twin to twin transfusion syndrome in 24 years old primigravida with gestational age of 18 weeks 5 days diagnosed on ultrasound.
\end{abstract}

Keywords: Anastomosis, Discordant, Donor, Monochorionic, Recipient, Twin-Twin

\section{INTRODUCTION}

Twin to twin transfusion syndrome is a rare but serious complication of multiple pregnancies that affects $5-10 \%$ of all monochorionic diamniotic gestations. ${ }^{1}$ It is caused by net intertwin transfusion of blood from one foetus (donor) to the other foetus (recipient) through abnormal placental vascular communication.

Overall incidence of perinatal mortality irrespective of gestational age is approximately $60 \%-70 \%$ and is almost $100 \%$ before 26 weeks. ${ }^{2-6}$ Its due to its poorly understood etiology and difficulty in diagnosing and treatment.

\section{CASE REPORT}

A 24 years old pregnant woman, primigravida with gestational age of 18 weeks 5 days came to this opd with complaint of backache for 2 days. She was an unbooked patient. She got her first ultrasound (level II) done at 18 weeks which revealed monochorionic diamniotic intrauterine live twins. Placenta was anterior with grade II maturity.

\section{$\operatorname{Twin} A$}

Maturity 19 weeks 4 days with foetal weight of 850 grams. It had polyhydramnios with single deepest pocket of $12 \mathrm{~cm}$. Foetal kidneys were normal with distended urinary bladder.

\section{Twin B}

Maturity 16 weeks with foetal weight of 300 grams. It had marked oligohydramnios. Foetal kidneys and urinary bladder were not seen. The diagnosis of twin to twin transfusion syndrome was made with twin $\mathrm{A}$ as donor twin and twin B as recipient twin as shown in Figure 1.

- On general examination

- Pulse rate - $88 / \mathrm{min}$

- $\quad$ Blood pressure - 102/80 mmHg

- Pallor - absent

- Afebrile to touch

Per abdomen examination- uterus 28 weeks $>$ period of gestation, tense to feel, foetal parts could not be palpable 
Per vaginum- cervix soft, midposition, os $1 \mathrm{~cm}$ dilated, $70-80 \%$ effaced, tense bag of membranes present, presenting part high up, pelvis adequate.

All investigations were within normal limit.

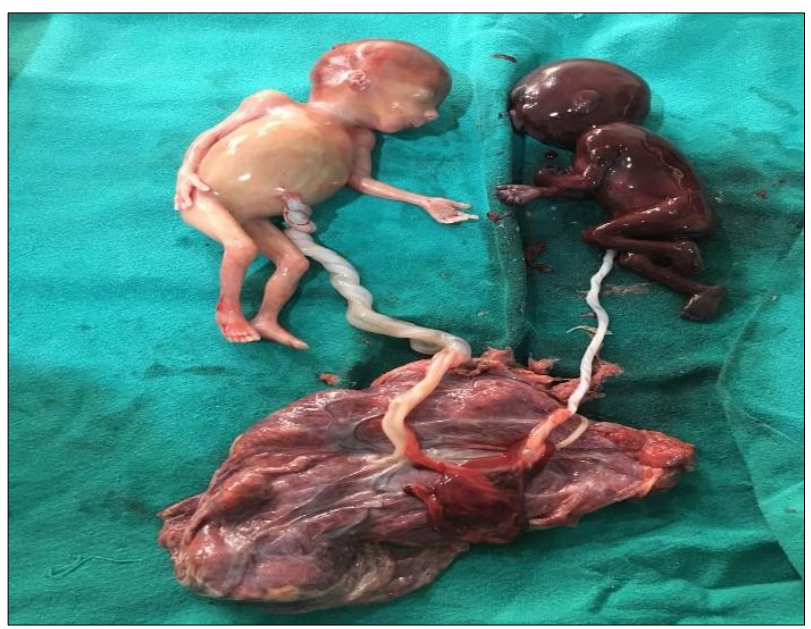

Figure 1: Twin A (donor) and Twin B (recipient).

As per patient's request, augmentation of labour was done with oxytocin and patient delivered uneventfully. The donor twin (Twin B) was hypovolemic, anaemic, smaller in size (in comparison to recipient (Twin A) with thin cord. The recipient twin (Twin A) was much bigger in size with oedematous cord, had polycythaemia and hydrops fetalis. Twin A (recipient) weighed 700 grams and Twin B (donor) 200 grams. There was $71.4 \%$ discordancy in foetal weight between the twins.

\section{DISCUSSION}

Twin to Twin transfusion syndrome presumed to arise from unbalanced anastomotic connections in the single, shared cotyledons of the placenta and is usually arteriovenous but may be arterio-arterial. ${ }^{7,8}$ This imbalance results in a shunting of blood from the high-pressure arterial circulation of one twin called the donor, to the low pressure venous system of the other twin called the recipient. ${ }^{9}$ This causes the recipient twin to become fluid overloaded, whereas the donor twin becomes hypovolemic.

Due to chronic hypovolemia, the donor twin becomes growth retarded, anaemic and produce little urine. This results in oligohydramnios and bladder may not be visible on the ultrasound. The twin gets wrapped by its amniotic membrane known as a stuck twin. To compensate for the extra volume of blood, the recipient twin excretes large amount of urine and results in large bladder on ultrasound and polyhydramnios. Hence the clinician has coined the term poly-oligo twins to describe the syndrome. ${ }^{1-3,9,10}$ The twins described in this case study were like this. The diagnosis of the twin to twin transfusion syndrome is made prenatally by ultrasound.
(A) According to the Sebire and coworker the ultrasound findings in the first trimester are ${ }^{11,12}$

- Presence of monochorionicity

- Increased nuchal translucency measurement > $3 \mathrm{~mm}$ between 10 and 14weeks of gestation

- Poor crown-rump length of one fetus

- Membrane folding at 10-13 weeks of gestation.

(B) Diagnostic criteria for twin twin transfusion syndrome in second trimester are ${ }^{13}$

\section{Monochorionic gestation}

- Same gender

- Single placental mass

- Thin dividing membrane

- Lack of lambda or twin peak sign.

\section{Abnormal amniotic fliud volume}

- One sac with oligohydramnios

- Deepest vertical pocket $<2 \mathrm{~cm}$

- One sac with polyhydramnios deepest vertical pocket $>8 \mathrm{~cm}$.

\section{Persistent urinary bladder findings}

- Small or no bladder visualized in twin with oligohydramnios

- Large bladder visualized in twin with polyhydramnios.

\section{Estimated fetal weight discordance (>20\% of larger twins estimated weight)}

\section{Appearance of stuck twin}

\section{Hydrops fetal (presence of one or more of the following)}

- Skin edema (> $5 \mathrm{~mm}$ thickness) of scalp skin

- Pericardial effusion

- Pleural effusion

- Ascites.

\section{Doppler findings}

- In the umbilical artery of the donor twin the diastolic flow can be either absent or reversed

- In the ductus venosus of the recipient twin the diastolic flow can be either absent or reversed.

The treatment of TTTS depends on ultrasound findings, the gestational age of the pregnancy and a couple's specific needs. The venous therapies are available like reduction, amniocentesis, septostomy (known as microseptostomy), selective laser ablation of the placental anastomotic vessels, radiofrequency ablation. If TTTS left untreated, it leads to the loss of one or both 
twins and if it occurs at a very early gestational age, the termination of the pregnancy can be considered due to grin prognosis. That target either the unequal fluid between the twins sacs or interrupt the blood vessels of communication between the twin on the single placenta. ${ }^{14}$

\section{CONCLUSION}

Twin to twin transfusion syndrome is an uncommon and severe complication of monochorionic multiple pregnancies which results in high perinatal mortality. TTTS is unpredictable in progression. However due to emergence of modern therapeutic modalities like serial amnioreduction, fetoscopic laser photocoagulation of vascular anastomosis, septostomy, removal of one twin at hysterotomy, percutaneous ultrasound guided umbilical cord ligation and close antepartum surveillance, there is a potential to improve the mortality and morbidity outcome associated with TTTS and perinatal mortality can be reduced to a great extent).

Funding: No funding sources

Conflict of interest: None declared

Ethical approval: Not required

\section{REFERENCES}

1. Bebbington MW, Wittmann BK. Fetal transfusion syndrome: antenatal factors predicting outcome. Am J Obstet Gynecol. 1989;160:913-5.

2. Blickstein I. The twin-twin transfusion syndrome. Obstetrics and Gynecology 1990;76:714-22.

3. Delia JE, Crusikshank DW, Keye WR. Fetoscopic neodymium: YAG laser occlusion of placental vessels in severe twin-twin transfusion syndrome. Obstet Gynecol. 1990;75:1046-53.

4. Elliot JP, Urig MA, Clewell WH. Aggressive therapeutic amniocentesis for treatment of twin-twin transfusion syndrome. Obstet Gynecol. 1991;77:53740.

5. Mahoney BS, Petty CN, Nyberg DA, Luthy DA, Hickok DE, Hirsch JH. The stuck twin phenomenon:
Ultrasonographic findings, pregnancy outcome and management with serial amniocentesis. Am J Obstet Gynecol. 1990;163:1513-22.

6. Urig MA, Clewell WH, Elliot JP. Twin-Twin transfusion syndrome. Am J Obstet Gynecol. 1990;163:1522-6.

7. Filly RA, Goldstrein RB, Callen PW. Monochorionic twinning: Sonograhic assessment. AJR. 1990;154:459-69.

8. Pretorious DH, Mahony BS. Twin gestations. In Nyberg DA, Mahony BS, Pretorious DH. Diagnostic ultrasound of fetal anomalies: Text and Atlas. Chicago Year Book Medical Publishers. 1990;592622.

9. Creasy R, Resnik R. Twin-Twin transfusion syndrome. Philadelphia: Saunders. Maternal-Fetal Med. 1989;565-579.

10. Wittman K, Farquharson DF, Thomas DS, Baldwin VJ, Wadsworth LD. The role of feticide in the management of severe twin transfusion syndrome. Am J Obstet Gynecol. 1986;155:1023-6.

11. Sebire NJ, D' Ercole C, Carbelho M, Sepulveda W, Nicolaides KH. Inter-twin membrane folding in monochorionic pregnancies. Ultrasound Obstet Gynecol. 1998;11:324-7.

12. Sebire NJ, D' Ercole C, Hughes K, Carvalho M, Nicolaides KH. Increased nuchal translucency thickness at 10-14 weeks of gestation as a predictor of severe twin-to-twin transfusion syndrome. Ultrasound Obstet Gynecol. 1997;10:86-9.

13. Arora V, Nijjar IS, Abrol R, Chopra R, Roopa. Twin-Twin transfusion syndrome. Ind J Radiol Imag. 2006;16(4):797-9.

14. Skupski DW. Twin-twin transfusion syndrome: an update. Croatian Med J. 2000;41(3):228-34.

Cite this article as: Bansal R, Kaur J, Priyanka.

Twin-Twin transfusion syndrome: a case report. Int J Reprod Contracept Obstet Gynecol 2020;9:1282-4. 